\title{
Psychometric properties of the Cognitive Fusion Questionnaire in females with fibromyalgia
}

\author{
Octavio Luque-Reca $^{1} \cdot$ David Gillanders ${ }^{2} \cdot$ Patricia Catala $^{1} \cdot$ Cecilia Peñacoba $^{1}$ (D)
}

Accepted: 7 August 2021

(C) The Author(s) 2021

\begin{abstract}
Cognitive fusion, or the degree to which a person is entangled with their thoughts and takes them literally, is considered a normal yet detrimental cognitive process associated with diverse negative outcomes across healthy and disordered functioning, including in fibromyalgia. Given the relevance of this cognitive process, the aim of the present study is to generate empirical evidence on the reliability and validity of the Cognitive Fusion Questionnaire (CFQ) in a sample of Spanish females with fibromyalgia. In this cross-sectional study, 230 Spanish females diagnosed with fibromyalgia (mean age 56.89 years; SD = 8.96) were assessed on cognitive fusion, pain catastrophizing, personality traits, positive and negative affect, anxiety symptoms, depressive symptoms and disease severity. Confirmatory factor analysis, reliability and validity analyses were performed. The CFQ showed a unidimensional structure, adequate temporal stability and good internal consistency. In addition, convergent and discriminant validity were found with respect to dispositional, pain-related, affective, mood and anxious measures; as well as incremental and criterion validity in the prediction of psychological symptoms or the disease severity status. The CFQ has been revealed as a solid and valid measure in the evaluation of cognitive fusion in Spanish females suffering from fibromyalgia, and may also be useful in clinical contexts due to the relationships it has shown with important outcomes. Limitations and future directions are also discussed.
\end{abstract}

Keywords Fibromyalgia $\cdot$ Cognitive fusion $\cdot$ Cognitive process $\cdot$ Assessment $\cdot$ Psychometric properties

\section{Introduction}

Fibromyalgia (FM) is a chronic disorder characterized by persistent and widespread musculoskeletal pain (Wolfe et al., 1990, 2010, 2018) and several non-pain related symptoms, such as fatigue, sleep problems and cognitive disturbances (Häuser et al., 2015). This syndrome mainly affects females (ranging from 61 to 90\%) (Wolfe et al., 2018) and its prevalence has been estimated to be around $2-4 \%$ in the general population (Wolfe et al., 2010). Regarding psychological aspects, estimates indicate that between 20 and $80 \%$ of FM patients have comorbid affective disorders such as depression and anxiety (Clauw, 2014). Thus, its physical and psychological symptoms cause the disease to constitute both a burden

Cecilia Peñacoba

cecilia.penacoba@urjc.es

1 Department of Psychology, Universidad Rey Juan Carlos, Avenida de Atenas s/n, 28922 Alcorcón, Madrid, Spain

2 School of Health in Social Science, University of Edinburgh, Teviot Place, Edinburgh, UK for patients and a public health problem that generates high economic, social and health costs (Arnold et al., 2016; Sicras-Mainar et al., 2009).

Cognitions have been shown to play a key role in adaptation to chronic pain conditions (De Ridder et al., 2008). Specifically, vulnerability factors such as pain catastrophizing or protective resources like self-efficacy in pain management have consistently demonstrated their relevance to the quality of life of individuals with FM (Angarita-Osorio et al., 2019; Estévez-López et al., 2018; Pulido-Martos et al., 2020).

However, as noted, pain is not the only symptom of FM and there are some authors who have explored the role of other cognitive variables of a general nature not exclusively linked to pain. Thus, it has been found that variables such as low frustration tolerance, self-deprecating style) (Suso-Ribera et al., 2016) or ruminative thinking (Malin \& Littlejohn, 2015) can act as vulnerability factors in patients experiencing chronic pain conditions. In this vein, a cognitive variable that is receiving increasing interest is cognitive fusion. This construct, developed from acceptance and commitment therapy (ACT) (Hayes et al., 2011), refers to the relationship a person has with his or her own cognitions (Gillanders et al., 2014, p. 
84). Specifically, it is defined as the degree to which a person thinks that the content of their thoughts fully reflects reality, that is, to what extent people react to their own thoughts as if they were an objective reality (Carvalho et al., 2018; Gillanders et al., 2014; Romero-Moreno et al., 2014, p. 119).

Among the instruments for assessing cognitive fusion, the Cognitive Fusion Questionnaire (CFQ) (Gillanders et al., 2014) is the most widely used measure (Cincidda et al., 2019). Psychometric properties of the CFQ Spanish translation have proven satisfactory (Romero-Moreno et al., 2014). Although there are other measures of cognitive fusion in the Spanish population, both in non-clinical (Ruiz et al., 2014; Valdivia-Salas et al., 2016) and in FM populations (Rodero et al., 2013), to our knowledge, the CFQ is the only one that evaluates this construct in a general way (without focusing on cognitions about a specific topic, such as anxious cognitions or cognitions about pain).

Angarita-Osorio et al. (2019) reported that cognitive fusion is associated with poorer function in people with FM, though that study used a pain specific measure of cognitive fusion. Evidence is beginning to accumulate from studies using the CFQ about the key role that this generic variable plays in patients with various chronic pain conditions. In particular, CFQ scores have been associated with pain intensity both in patients without rheumatic disease (Özkan et al., 2017) and in patients with heterogeneous chronic pain conditions (Carvalho et al., 2018). Significant associations have also been found between CFQ and pain catastrophizing in patients with both FM (Écija et al., 2020) and without rheumatic disease (Özkan et al., 2017). In patients experiencing FM or chronic pain conditions, cognitive fusion has also been linked to lower vitality (McCracken et al., 2014), increased physical fatigue (Écija et al., 2020) and poorer perceived general health (McCracken et al., 2014). Cognitive fusion assessed with the CFQ has also been related to anxious and depressed symptoms (McCracken et al., 2014) in cross-sectional (Écija et al., 2020; Carvalho et al., 2018; McCracken et al., 2014) and longitudinal studies (Carvalho et al., 2019). Additionally, although there is no evidence in patients with FM or other rheumatic diseases, cognitive fusion has also been significantly related to personality variables such as neuroticism (Momeniarbat et al., 2017) and affective variables such as positive and negative affect (Bolderston et al., 2019).

Given that cognitive fusion appears to be a detrimental cognitive process linked to negative outcomes in patients with FM (Carvalho et al., 2018, 2019; Écija et al., 2020), a solid and valid instrument to assess this cognitive vulnerability factor would prove invaluable for research with FM population. Currently, the CFQ is validated in Spain in a sample of caregivers of relatives with dementia (Romero-Moreno et al., 2014), but, to our knowledge, not with FM or other chronic pain patients. Thus, the aim of the present study is to generate empirical evidence on the reliability and validity of the CFQ in a Spanish FM sample.

\section{Method}

\section{Participants}

In this study, 230 Spanish females with FM between the ages of 30 and 78 ( $\mathrm{M}=56.89$ years, $\mathrm{SD}=8.96$ years $)$ were evaluated on the variables of interest. Table 1 presents the sociodemographic data and the clinical characteristics of the participating females. Out of the 230 participants, 90 were selected (by a random number generator) to reassess their levels of cognitive fusion two months after the first evaluation,

Table 1 Study participants' socio-demographic and clinical characteristics $(\mathrm{n}=230)$

\begin{tabular}{|c|c|c|}
\hline Age (30 to 78 years), mean $(S D)$ & 56.89 & $(8.96)$ \\
\hline \multicolumn{3}{|l|}{ Level of education, $n(\%)$} \\
\hline Unfinished primary education & 30 & $(13.00)$ \\
\hline Primary education & 121 & $(52.60)$ \\
\hline Secondary (and vocational) education & 61 & $(26.50)$ \\
\hline University education & 15 & $(6.50)$ \\
\hline Missing data & 3 & $(1.30)$ \\
\hline \multicolumn{3}{|l|}{ Marriage status, $n(\%)$} \\
\hline Single & 12 & $(5.20)$ \\
\hline Married (or cohabiting together) & 181 & $(78.70)$ \\
\hline Divorced/separated & 20 & $(8.70)$ \\
\hline Widowed & 16 & $(7.00)$ \\
\hline Missing data & 1 & $(0.40)$ \\
\hline \multicolumn{3}{|l|}{ Employment situation, $n(\%)$} \\
\hline Domestic work & 76 & $(33.00)$ \\
\hline Unemployed & 28 & $(12.20)$ \\
\hline Working & 28 & $(12.20)$ \\
\hline Pensioned not due to pain issues & 32 & $(13.90)$ \\
\hline Pensioned because of pain issues & 41 & $(17.80)$ \\
\hline Medical leave & 23 & $(10.00)$ \\
\hline Missing data & 2 & $(0.90)$ \\
\hline Years after diagnosis of FM (1 to 46$)$, mean $(S D)$ & 12.10 & $(8.45)$ \\
\hline Missing data & 5 & $(2.20)$ \\
\hline Antidepressant medication, $n(\%)$ & 144 & $(62.60)$ \\
\hline Missing data & 13 & $(5.70)$ \\
\hline Analgesic medication, $n(\%)$ & 193 & $(83.90)$ \\
\hline Missing data & 9 & $(3.90)$ \\
\hline Sleep medication, $n(\%)$ & 129 & $(56.10)$ \\
\hline Missing data & 12 & $(5.20)$ \\
\hline Muscle relaxant medication, $n(\%)$ & 80 & $(34.80)$ \\
\hline Missing data & 18 & $(7.80)$ \\
\hline
\end{tabular}

SD Standard Deviation 
among them, 62 agreed and were finally reevaluated. Participation in this study had three inclusion criteria: (i) being older than 18 years of age; (ii) having a FM diagnosis based on the criteria established by the American College of Rheumatology (ACR) (Wolfe et al., 1990, 2010); and (iii) giving written consent to participate in the present research. The recruitment of participants took place by contacting with pain support associations across the country (Albacete, Toledo, Madrid, Ciudad Real, and Guadalajara). This study obtained the approval of the Rey Juan Carlos University Ethics Committee (reference code PI-17/00858 and project number 160520165916) and written informed consent for anonymous analysis of data was retrieved from all participants. The ethical guidelines for research with human participants of the Helsinki Declaration were met.

\section{Measures}

Socio-demographic (i.e., age, level of education, marriage status, and employment situation) and clinical variables (i.e., time since the diagnosis of FM, antidepressant medication, analgesic medication, sleep medication, and muscle relaxants intake) were evaluated using a questionnaire created for this study.

Cognitive fusion was assessed using the Spanish version of the CFQ developed by Romero-Moreno et al. (2014). The instrument comprises seven items using a Likert-type response format of seven points that ranges from 1 to 7 . Higher scores on this scale indicate a more marked cognitive fusion. This measure contains items like "I get so caught up in my thoughts that I am unable to do the things that I most want to do" and the overall score ranges from 7 to 49 . Cronbach's alpha of both the original version of the scale (.80 to .90 with different samples) and the Spanish version (.87) was high in both cases.

The Spanish validation developed by Garcia-Campayo et al. (2008) of the Pain Catastrophizing Scale (PCS; Sullivan et al., 1995) was used to assess the level of catastrophizing with regard to pain, conceived as an excessive pessimistic orientation in relation to present or anticipated experiences of pain (Garcia-Campayo et al., 2008; Sullivan et al., 1995, p. 524). This measure contains three subscales that evaluate the three components of the construct: magnification, rumination and helplessness. Magnification refers to an overestimation regarding to the unpleasantness of painful events and the expectations of experiencing adverse outcomes; rumination relates to worry, ruminative thoughts, and an inefficacy to inhibit thoughts related to pain; and helplessness includes negative evaluations regarding the ability to efficiently handle pain stimuli (Sullivan et al., 1995, p. 525). The instrument contains 13 items that use a Likert-type format of four points, with high scores denoting a higher degree of pain catastrophizing. The Spanish adaptation possess adequate psychometric properties, reporting good reliability (internal consistency) for both the overall score (.79) and the subscales (ranging between .74 and .82) (Garcia-Campayo et al., 2008). Good internal consistency was found in this study for both the total score (.94) and the subscales (.78 for magnification, .87 for rumination and .89 for helplessness).

Personality traits were assessed by the Spanish validation of the NEO Five-Factor Inventory (NEO-FFI) developed by Seisdedos (1999), which includes 60 items using a Likert-type response format of five points that evaluate the five principal personality traits: neuroticism, extraversion, conscientiousness, agreeableness, and openness. Every single subscale or dimension can be scored between 0 and 48. Higher scores on the subscales reflect more pronounced personality traits. The internal consistency reported by the Spanish version was good (Cronbach's alphas ranging between .82 and .90) (Seisdedos, 1999). In this study, reliability was good for some traits $(.83, .74$, and .80 for neuroticism, extraversion and conscientiousness, respectively) and acceptable to low for others (.60 and .64 for openness and agreeableness, respectively).

Depressive and anxious symptoms over the preceding week were measured with the Spanish version of the Hospital Anxiety and Depression Scale (HADS; Zigmond $\&$ Snaith, 1983) (Herrero et al., 2003). The HADS is a 14 item measure with a Likert response format of four points, designed to be used with non-psychiatric populations. The depression and anxiety subscales each have 7 items, higher scores represent higher depressive or anxious symptomatology. This measure, characterized by avoiding evaluating the somatic manifestations of emotional disorders in order not to over-diagnose anxiety or depression in patients suffering from physical conditions, has been specifically validated in the Spanish population with FM (Luciano et al., 2014a). The reliability reported by the authors of the Spanish version was high for both subscales (.84 and $.85)$, as it was in the present study (.85 and .80$)$.

Participants' positive and negative affect levels were evaluated with the Spanish version of the Positive and Negative Affect Schedule (PANAS) developed by Sandin et al. (1999). This 20-item measure with a Likert response format of five points evaluates the individual's usual affective state. The 10 -item positive affect subscale assess positive affective or emotional states (e.g., enthusiastic), whereas the 10-item negative affect subscale assess negative emotional states (e.g., scared). Adequate construct validity has been found in studies that have used this scale in females with FM (Estévez-López et al., 2016). As reported by the authors of the Spanish version (Sandin et al., 1999), Cronbach's alphas of both positive (.89 and .87 for males and females, respectively) and negative (.91 and .89 for males and females, respectively) affect subscale 
were high. Similarly, internal consistency was high for both positive (.91) and negative affect (.87) in this study.

FM severity was measured using the Spanish adaptation of the Revised Fibromyalgia Impact Questionnaire (FIQ-R) developed by Salgueiro et al. (2013), which is composed of 21 items with a numerical response format of 11 points that evaluate three associated areas: overall impact, physical function and symptoms. The subscale termed overall impact is composed of 2 items which evaluate to what extent FM prevented the attainment of objectives or the realization of plans desired by the person; the subscale named physical function comprises 9 items or statements that assess the degree to which difficulties are experienced in doing certain ordinary physical activities of regular life; and the 10 items belonging to the subdimension termed symptoms evaluate the degree to which a variety of symptoms of a diverse nature (cognitive, emotional, bodily) were experienced. This scale also allows the computation of a total score (ranging between 0 and 100), with higher values denoting greater effect of FM on the individual's quality of life. The internal consistency obtained by the three domains ranged from .81 and .92, and the total score was also reliable (.91 to .95 with different samples) (Luciano et al., 2013; Salgueiro et al., 2013), as it was in the present research $(.87, .80, .85$, and .92 for physical function, overall impact, symptoms and the total severity score, respectively).

\section{Analysis}

Statistical Package for the Social Sciences (SPSS) version 22 (IBM Corporation, Armonk, USA) was employed for: (i) examining missing data, (ii) descriptive analyses, (iii) convergent/divergent validity analyses, and (iv) criterion validity analyses. EQS version 6.2 (Multivariate Software Incorporation, Encino, USA) was employed to explore multivariate normality and to perform both confirmatory factor analysis and reliability analysis using structural equation modeling methodology (SEM). Visual inspection of patterns of missing data confirmed that such absent values seemed to be missing completely at random (MCAR), with the overall amount of missing data equaling less than 5\% (1 observation and $0.4 \%$ of missing values) of the sample, confirming that reliability of the data was not negatively affected (Graham, 2009). In line with Garson's (2012) recommendations, the one case with missing values was eliminated (listwise deletion), leading to a sample size to 230 participants. The standardized Mardia's coefficient of 17.59, showed the data were not multivariate normal, and therefore robust maximum likelihood estimation was used in confirmatory factor analysis (CFA) (Ullman, 2006).

For the purpose of exploring the CFQ factor structure (construct validity), CFA was conducted to examine the configuration presented by the authors who developed the original scale (Gillanders et al., 2014) and the Spanish version for caregivers (Romero-Moreno et al., 2014). The adjustment of the model was evaluated using SEM. Although there are estimation methods such as the diagonally weighted least squares designed specifically to deal with categorical data (Li, 2016), the robust maximum likelihood (MLR) estimation method has been used in the present study. This alternative was chosen since other studies support that in conditions of non-normality and when there are variables with five or more response alternatives ( 7 in this case), these can be treated as if they were continuous and thus use MLR to evaluate the adjustment of the model (Raykov, 2012). The selected indexes to assess model fit were: the scaled chi-square statistic developed by Satorra and Bentler (1994) (S-B $\chi^{2}$ ) with its associated $\mathrm{p}$ value and degrees of freedom (df); the incremental fit index called Comparative Fit Index (CFI); and the absolute fit index referred to as Root Mean Square Error of Approximation (RMSEA), accompanied by its $90 \%$ confidence interval (CI). Considering the sample size below 250 subjects and the reduced amount of indicators or observed variables, the adequacy of the model (i.e., good fit) was determined based on the following cutoff points: $\mathrm{S}-\mathrm{B} \chi^{2} \mathrm{p}$ value $\geq .05, \mathrm{CFI} \geq$ .97 , and RMSEA $\leq .08$ (Hair et al., 2014). To test whether the modification of a model significantly improves the fit with respect to the previous model, the S-B $\chi^{2}$ scaled difference test (Satorra \& Bentler, 2001) was used, with $\mathrm{p}$ value $<.05$ indicating a better adjustment. Additionally, the model's local adjustment was evaluated by both the standardized factor loadings $(\lambda)$ and the item's individual reliability $\left(\mathrm{R}^{2}\right)$. Following Hair et al. (2014) and Marôco (2010), values of $\lambda \geq .70$ and $\geq .50$ are considered good and acceptable, respectively; whilst $\mathrm{R}^{2}$ values $\geq .50$ and $\geq .25$ are considered good and acceptable, respectively.

Later, the CFA-based scale reliability was assessed. Since in SEM methodology conventional estimators of internal consistency (e.g., coefficient alpha) can alter reliability, underestimating or overestimating it (Garson, 2012), and are not considered adequate when error terms are correlated (Hankins, 2008), internal consistency of the CFQ was calculated using the Raykov's Rho coefficient (frequently known as composite reliability; CR). In line with Hair et al. (2014) recommendations, CR scores over .70 are adequate. In those participants who answered the scale again after two months $(n=62)$, the intraclass correlation coefficient (abbreviated as the ICC) was used to explore test-retest reliability, considering values $\geq .70$ as adequate (Cicchetti, 1994).

Bivariate correlations between the CFQ score and those variables that were theoretically associated with cognitive fusion (pain catastrophizing, personality traits, positive affect, and negative affect) were conducted to analyze convergent and discriminant validity. 
Finally, multiple linear regression analyses were also performed in order to assess incremental validity, exploring the independent associations of cognitive fusion with the psychological outcomes of anxiety and depression, after controlling for other factors that previously have been shown to contribute significantly to such outcomes (Haynes \& Lench, 2003). Furthermore, criterion validity was explored by conducting t-test comparisons in the CFQ score between participants with mild anxiety/depression or without anxiety/depression (scores $\geq 11$ ) and those participants with moderate or severe anxiety/ depression (scores $<11$ ). Similarly, a $t$-test was performed to compare the CFQ score between participants with higher disease severity (scores $>65$ ) and those with moderate or mild FM severity (scores $\leq 65$ ). These cut-off points on the severity of the disease or its mood symptoms have been previously used in various studies with individuals suffering from FM (Aparicio et al., 2013; Salaffi et al., 2018) and other conditions (Zigmond \& Snaith, 1983). Cohen's $d$ (Cohen, 1988) was computed to analyze the magnitude of these differences, with values of $.20, .50$, and .80 representing small, medium, and large effect sizes, respectively.

\section{Results}

Following the proposal of the authors of the original scale and the Spanish version for caregivers (Gillanders et al., 2014; Romero-Moreno et al., 2014), the adjustment of a unifactorial structure made up of the 7 items of the instrument was tested. The results showed an unsatisfactory fit of this first model (see Table 2). Factor loadings and communalities of the items were adequate ( $\lambda$ ranged from .69 to .88 and $R^{2}$ ranged from .48 to .78). Modification indices suggested that incorporating a covariance between certain item error terms (specifically, between items 1 and 2) would improve the overall fit of the model. Even though it is common to employ this procedure among items belonging to the same factor, it is only justified when there are substantive theoretical reasons that support it (Garson, 2012). In this case, previous studies with the CFQ have correlated both items ("My thoughts cause me distress or emotional pain" and "I get so caught up in my thoughts that I am unable to do the things that I most want to do") (Lucena-Santos et al., 2017), because they are statements that refer specifically to thoughts that generate negative consequences for the person (emotional or behavioral limitations, specifically). Thus, a second one-factor model identical to the previous one but in which a correlation was added between the error terms of items 1 and 2 was tested. In this case, the modified model obtained an excellent fit (see Table 2) and factor loadings and communalities of the items were adequate $\left(\lambda\right.$ ranged from .66 to .89 and $\mathrm{R}^{2}$ ranged from .43 to .79 ; see Fig. 1). After comparing them, the modified model showed a significantly better fit than the initial model (S-B $\chi^{2}$ scaled difference $=14.00, \mathrm{df}=1, \mathrm{p}<.001)$.

The internal consistency of the scale was shown to be excellent in the present sample $(\mathrm{CR}=.90)$. The randomly drawn retest sample was compared to the total sample on the CFQ and socio-demographic variables and no significant differences were found. Test-retest reliability in the retest sample was .71.

Regarding convergent and discriminant validity, the scale showed significant associations with cognitive variables linked to pain, with certain personality traits and with affective variables (see Table 3 ). Specifically, low magnitude correlations were established both with positive affect and with extraversion and conscientiousness traits; moderate-low magnitude correlations with disease severity, depression and pain catastrophizing and its dimensions; and moderate-high magnitude correlations with neuroticism, negative affect and anxiety. Additionally, the CFQ average score of the Spanish females with FM (see Table 3) was higher than those obtained in young adults in the original article $(\mathrm{M}=22.28, \mathrm{SD}=8.30$; Gillanders et al., 2014), in Spanish caregivers of people with dementia ( $\mathrm{M}=25.28, \mathrm{SD}=9.68$; Romero-Moreno et al., 2014), and even in Portuguese females with various chronic pain conditions $(\mathrm{M}=23.76, \mathrm{SD}=10.83$; Carvalho et al., 2019); being only surpassed by people with mental health difficulties in the original study $(\mathrm{M}=34.31, \mathrm{SD}=8.06$; Gillanders et al., 2014).

Incremental validity was explored performing two multiple linear regression analyses (see Table 4) using the enter method. The first analysis, with anxiety as criterion variable, showed that cognitive fusion explained an additional percentage of variance (3.2\%), beyond that explained by neuroticism and pain catastrophizing. Using depression as criterion variable, cognitive fusion also explained a significant amount of incremental variance $(1.5 \%)$ over that explained by affect (positive and negative) and pain catastrophizing.
Table 2 Goodness of fit indexes for the models tested

\begin{tabular}{lcccccc}
\hline & S-B $\chi^{2}$ & $d f$ & $p$ & CFI & RMSEA & RMSEA 90\% CI \\
\hline One factor & 43.265 & 14 & $<.001$ & .960 & .095 & {$[.064-.128]$} \\
$\begin{array}{l}\text { One factor with item 1 and } \\
\text { item 2 correlated errors }\end{array}$ & 15.610 & 13 & .271 & .996 & .030 & {$[.000-.075]$} \\
\hline
\end{tabular}




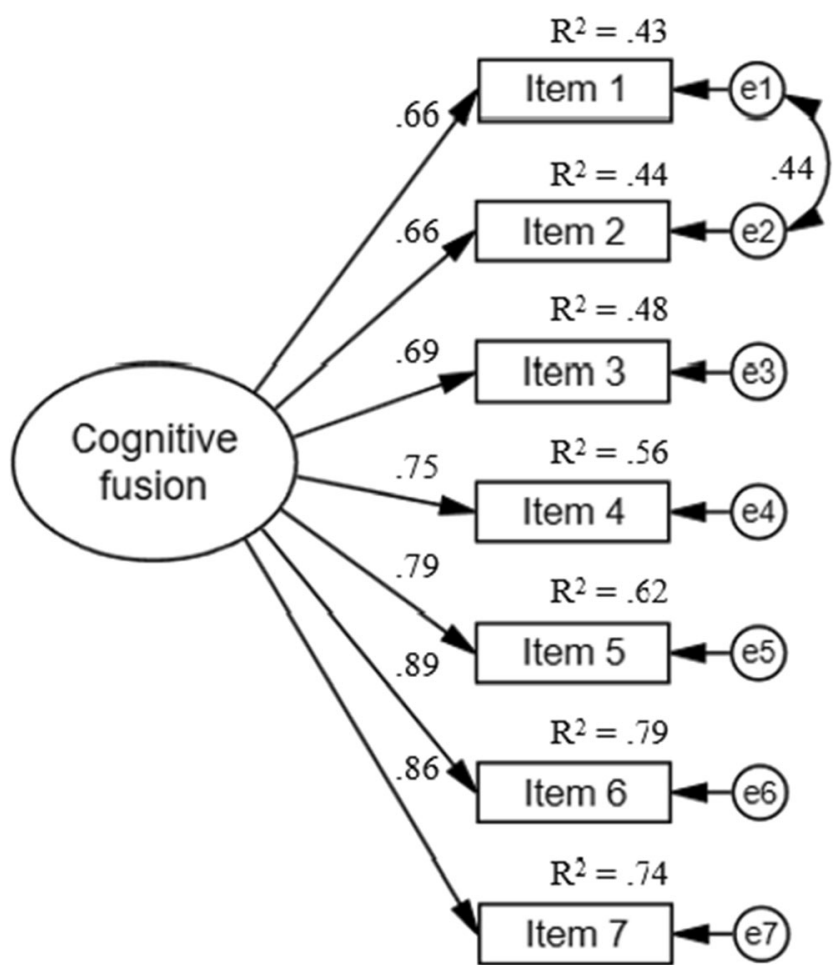

Fig. 1 Factor loadings and communalities of the CFQ one-factor structure with two correlated error terms

In relation to criterion validity, significant differences in cognitive fusion levels were found between participants with probable mood or anxiety disorders and those without (see

Table 3 Descriptives and Pearson correlations (r) between CFQ and pain catastrophizing, personality traits, affect, anxiety, depression and disease severity $(n=230)$

\begin{tabular}{lllll}
\hline & $\mathrm{r}$ & $p$ & $\mathrm{M}$ & $\mathrm{SD}$ \\
\hline Cognitive fusion [CFQ] & & & 33.31 & 9.62 \\
Overall pain catastrophizing [PCS] & .45 & $<.001$ & 31.89 & 11.65 \\
Rumination [PCS] & .37 & $<.001$ & 10.19 & 4.05 \\
Magnification [PCS] & .41 & $<.001$ & 6.63 & 3.09 \\
Helplessness [PCS] & .44 & $<.001$ & 15.06 & 5.59 \\
Neuroticism [NEO-FFI] & .64 & $<.001$ & 40.02 & 8.94 \\
Extraversion [NEO-FFI] & -.31 & $<.001$ & 36.40 & 8.17 \\
Conscientiousness [NEO-FFI] & -.20 & .003 & 42.26 & 6.97 \\
Openness [NEO-FFI] & -.08 & .234 & 37.53 & 6.50 \\
Agreeableness [NEO-FFI] & -.10 & .888 & 47.03 & 5.93 \\
Positive affect [PANAS] & -.21 & .001 & 30.83 & 9.04 \\
Negative affect [PANAS] & .64 & $<.001$ & 29.78 & 8.53 \\
Anxiety symptoms [HADS] & .63 & $<.001$ & 12.23 & 3.88 \\
Depressive symptoms [HADS] & .50 & $<.001$ & 9.23 & 4.29 \\
Disease severity [FIQ-R] & .45 & $<.001$ & 72.37 & 17.04 \\
Physical function [FIQ-R] & .28 & $<.001$ & 21.30 & 5.72 \\
Impact [FIQ-R] & .40 & $<.001$ & 13.63 & 5.35 \\
Symptoms [FIQ-R] & .50 & $<.001$ & 37.43 & 8.10 \\
\hline
\end{tabular}

Table 5). Likewise, there were significant differences in the CFQ between patients with high FM severity and those with mild or moderate disease severity. The effect sizes ranged from medium to large (see Table 5).

\section{Discussion}

Cognitive fusion has been shown to be a detrimental cognitive process that seems to increase vulnerability to various negative FM outcomes (Carvalho et al., 2018, 2019; Écija et al., 2020). For this reason, it is of great interest to have sufficiently solid instruments in the Spanish language that can assess this process in people with FM.

Although there are cognitive fusion measures specifically designed for people with chronic pain conditions (Rodero et al., 2013), it seems that instead of evaluating the degree of fusion with one's thoughts, their items rather measure the individual's desire or commitment for understanding, fighting or reducing pain. Thus, this work focuses on the CFQ (Gillanders et al., 2014) since, in addition to being the most widely used cognitive fusion instrument (Cincidda et al., 2019), it is considered more appropriate to evaluate this construct in a general way due to the wide variety of symptoms of FM, which are not limited exclusively to pain (Häuser et al., 2015). The Spanish version of the CFQ available to date has adequate psychometric properties which, however, have been confirmed in a very specific population and different from that of patients with chronic pain: caregivers of relatives with dementia (Romero-Moreno et al., 2014). Therefore, this study aimed to contribute to the field by exploring in depth the psychometric properties of the CFQ in a sample of Spanish females with FM.

The present findings show that the Spanish version of the CFQ (Romero-Moreno et al., 2014) presents adequate psychometric properties, constituting a useful instrument for evaluating cognitive fusion in Spanish women with FM. First, the results of the confirmatory factor analysis supported a unifactorial structure of the scale, in line with the original and Spanish versions (Gillanders et al., 2014; Romero-Moreno et al., 2014). In particular, similar to the Brazilian version of the CFQ (Lucena-Santos et al., 2017), the unifactorial model with a covariance between the measurement errors of items 1 and 2 obtained an excellent fit. In addition, factor loadings and communalities of the 7 items were adequate. The internal consistency of the scale was excellent and very similar to both the original version (Gillanders et al., 2014) and the Spanish version in a caregiver sample (Romero-Moreno et al., 2014), suggesting that the items provide similar scores when evaluating the construct. Regarding test-retest reliability, which was not tested in the aforementioned Spanish version (Romero-Moreno et al., 
Table 4 Multiple linear regression of the independent associations of cognitive fusion with anxiety and depressive symptoms $(\mathrm{n}=230)$

\begin{tabular}{|c|c|c|c|c|c|c|c|c|c|}
\hline & \multicolumn{4}{|c|}{ Anxiety symptoms } & & \multicolumn{4}{|c|}{ Depressive symptoms } \\
\hline & $\beta$ & $p$ & $\Delta$ Adj. $R^{2}$ & $p$ & & $\beta$ & $p$ & $\Delta$ Adj. $R^{2}$ & $p$ \\
\hline Predictors & & & & & Predictors & & & & \\
\hline Step 1 & & & .429 & $<.001$ & Step 1 & & & .296 & $<.001$ \\
\hline Neuroticism & .657 & $<.001$ & & & Neuroticism & .547 & $<.001$ & & \\
\hline Step 2 & & & .071 & $<.001$ & Step 2 & & & .171 & $<.001$ \\
\hline Positive affect & -.037 & .192 & & & Positive affect & -.397 & $<.001$ & & \\
\hline Negative affect & .393 & $<.001$ & & & Negative affect & .410 & $<.001$ & & \\
\hline Step 3 & & & .002 & .158 & Step 3 & & & .016 & .005 \\
\hline Pain catastrophizing & .080 & .158 & & & Pain catastrophizing & .162 & .005 & & \\
\hline Step 4 & & & .032 & $<.001$ & Step 4 & & & .015 & .006 \\
\hline $\begin{array}{l}\text { Cognitive fusion } \\
\text { Total adjusted } R^{2}\end{array}$ & .254 & $<.001$ & .534 & & $\begin{array}{l}\text { Cognitive fusion } \\
\text { Total adjusted } R^{2}\end{array}$ & .184 & .006 & & \\
\hline
\end{tabular}

$\Delta$ Adj. $R^{2}$, change in adjusted $R^{2}$ with significance levels on $F$-change

2014), it was adequate, although lower than that reported in the original scale (Gillanders et al., 2014).

In this study, the CFQ was also revealed as a valid instrument to be used in females with FM. Specifically, the CFQ showed low-moderate correlations with pain catastrophizing and its dimensions. This suggests that both are related processes, although are sufficiently differentiated to be distinct constructs. This is further supported by previous studies that found that cognitive fusion and the components of catastrophizing relate differently to different FM outcomes (Écija et al., 2020). Low negative correlations with extraversion and conscientiousness traits were also obtained, as well as moderate-high negative correlations with neuroticism. Although there is no prior research that addresses the relationship of cognitive fusion with Big-Five personality traits, these findings are consistent with those obtained in patients with diabetes, where a very similar correlation was found between neuroticism evaluated in isolation and the CFQ (Momeniarbat et al., 2017). Thus, the absence of high correlations with personality traits could indicate that cognitive fusion, despite being a process associated with individual tendencies (Gillanders et al., 2014), does not present a conceptual overlap with personality traits. The associations found with affective variables were also in the expected direction (Bolderston et al., 2019), finding correlations of low and moderate high magnitude with positive affect and negative affect, respectively. Given that some CFQ items expressly refer to emotional pain or anger, it is logical to find high correlations with negative affectivity. Concurrently, and in line with the previous literature in patients with rheumatic diseases (Carvalho et al., 2018, 2019; Écija et al., 2020; McCracken et al., 2014), cognitive fusion was also significantly related to anxious and depressive symptoms in females with FM. Finally, the CFQ score was moderately associated with overall disease severity, supporting the findings of previous studies with a pain specific instrument of cognitive fusion (Angarita-Osorio et al., 20192019). Furthermore, the FIQ-R showed low associations between CFQ and physical functioning and moderate associations with symptoms and impact of FM. These findings,
Table 5 Mean differences in cognitive fusion in participants' anxiety, depression and severity status $(\mathrm{n}=230)$

\begin{tabular}{lllllll}
\hline & $n$ & Mean & $S D$ & $t$ & $p$ & Cohen's $d$ \\
\hline Anxious disorder* & 155 & 36.68 & 7.87 & -8.85 & $<.001$ & 1.25 \\
Non-anxious disorder & 75 & 26.33 & 9.16 & & & \\
Depressive disorder* & 92 & 37.83 & 8.14 & -6.29 & $<.001$ & 0.85 \\
Non-depressive disorder & 138 & 30.30 & 9.36 & & & \\
High FM severity & 161 & 35.29 & 8.83 & -5.26 & $<.001$ & 0.72 \\
Low-moderate FM severity & 69 & 28.70 & 9.85 & & &
\end{tabular}

*probable anxious or depressive disorder defined as scoring equal to or above 11 on the HADS subscale (Aparicio et al., 2013) 
although correlational and not causal, suggest that the degree to which a person is fused with their thoughts is associated with increased reporting of bodily, cognitive and emotional symptoms and a reduced appraisal of being able to achieve their goals. All these results underscore the adequate convergent and discriminant validity of the CFQ with respect to diverse variables that have been shown to be important in the course and the involvement of FM.

The Spanish CFQ also exhibits adequate incremental validity, explaining modest but significant percentages of additional variance after controlling for well-established variables in the relationship between FM and anxiety and depression (Hassett et al., 2008; Malin \& Littlejohn, 2012). More specifically, in contrast to a variable that plays a key role in FM such as pain catastrophizing, cognitive fusion evaluated with the CFQ manages to explain an additional percentage of variance of anxiety symptoms, in addition to explaining the same percentage of variance of depressive symptomatology as this pain related variable. In this vein, it has been proposed that people with pain symptoms that are more fused with their thoughts would have greater difficulty implementing adaptive coping strategies in situations that are perceived as threatening (Luoma et al., 2007). These findings support the idea that, also in females with FM, psychological distress could be related not only to the presence and intensity of dysfunctional thoughts, but also to the degree to which the person fuses with said thoughts (Romero-Moreno et al., 2014).

Furthermore, it is important to mention that the results of the present study show that, compared to both the general population without chronic disease and other chronic pain populations (Carvalho et al., 2019; Gillanders et al., 2014; Romero-Moreno et al., 2014), Spanish females with FM seem to be very fused with their thoughts. Therefore, these results are in line with the previous evidence about the relevance of this cognitive process in the course of the disease (Carvalho et al., 2018, 2019; Écija et al., 2020).

Having shown criterion validity regarding the severity of the disease and its anxious-depressive symptoms, the CFQ could be used in clinical practice to identify those patients with FM who are likely to benefit more from interventions to reduce cognitive fusion aimed at maximizing living effectively with the disease. These findings allow future studies to use the Spanish CFQ to track people's responses to these psychological interventions and, in line with previous studies (Trompetter et al., 2015), conduct larger research trials that shed light on the cognitive processes that mediate psychological therapies for FM.

The study had several limitations, such as the use of a non-representative convenience sample of the Spanish population with FM. This suggests caution when generalizing the results of this scale to other population groups or subgroups (e.g., males with FM). In this vein, despite being a reasonably minority population (Wolfe et al., 2010), the relatively small sample size and the use of a single sample to assess the psychometric properties of the scale should also be highlighted. Thus, we recommend that future studies focus on replicating the present findings in more diverse samples, and may even explore the measurement invariance of the scale in different subgroups (e.g., depending on gender, age, etc.). Another limitation is not having used other general cognitive variables (e.g., rumination, experiential avoidance, self-efficacy, etc.) that would allow a more exhaustive exploration of the discriminant validity of the CFQ. Furthermore, despite the considerable importance that subjective experience has in pain-related disorders (Robinson et al., 2013), the use of self-report measures is also a limitation, since objective and subjective measures often differ in the study of FM (Munguía-Izquierdo et al., 2019). Finally, due to the cross-sectional nature of our study, we cannot draw causal relationships between the assessed variables, so future longitudinal and experimental studies are necessary.

Despite the aforementioned limitations, the findings of the present study have a series of relevant implications. On the one hand, the adequate psychometric properties demonstrated by the CFQ in females with FM, together with its brevity and speed of completion, make this scale a very useful instrument in various types of studies and in clinical work. Therefore, as the authors of the original version point out, this instrument is especially suitable for use in initial evaluations in clinical settings, as well as to be employed repeatedly to track changes in the level of cognitive fusion or associated variables (Gillanders et al., 2014). On the other hand, and in line with experimental research in the general population (Masuda et al., 2010), it could be very useful to practice the ability of FM patients to distance themselves from their own thoughts (i.e., cognitive defusion), since this could promote more adaptive responses to the situations of psychological distress experienced daily. In fact, although still scarce, there are interventions developed from ACT that train cognitive defusion in people with FM that have been shown to produce a significant improvement in the levels of anxiety, depression and disease severity (Hughes et al., 2017; Luciano et al., 2014b). In conclusion, the CFQ has been revealed as a sufficiently robust and valid measure in the evaluation of cognitive fusion in Spanish females suffering from FM, and may also be useful at the clinical level due to the relationships it has shown with important outcomes.

Supplementary Information The online version contains supplementary material available at https://doi.org/10.1007/s12144-021-02214-4.

Author Contributions Conceptualization, O.L.R., D.G., P.C., and C.P.; funding acquisition, C.P.; methodology, O.L.R., D.G., and C.P; software, O.L.R.; formal analysis, O.L.R.; validation, O.L.R.; investigation, O.L. R., P.C., and C.P.; resources, O.L.R., P.C., and C.P.; data curation, O.L. R., P.C., and C.P.; visualization, O.L.R., D.G., and C.P.; writingoriginal draft preparation, O.L.R., D.G., P.C., and C.P.; writingreview and editing, O.L.R., D.G., and C.P.; supervision, C.P.; project administration, C.P. All authors have read and agreed to the published version of the manuscript. 
Funding Open Access funding provided thanks to the CRUE-CSIC agreement with Springer Nature. The present study was funded by the Health Research Fund from the Instituto de Salud Carlos III (Spain), under grant number PI17/00858, and was co-financed by the European Union through the Fondo Europeo de Desarrollo Regional (FEDER).

Data Availability Datasets generated and/or analyzed during the present research are available from the corresponding author on reasonable demand.

\section{Declarations}

Conflict of Interest No conflict of interest is declared by the authors.

Ethics Approval All procedures with human participants conducted during the present study met the ethical requirements of the institutional and/ or national research committee and were in accordance with the 1964 Helsinki Declaration and its subsequent amendments. This study was also approved by the Bioethics Committee of the Universidad Rey Juan Carlos (Reference PI17/00858; number 160520165916).

Consent to Participate All study participants gave their informed consent.

Open Access This article is licensed under a Creative Commons Attribution 4.0 International License, which permits use, sharing, adaptation, distribution and reproduction in any medium or format, as long as you give appropriate credit to the original author(s) and the source, provide a link to the Creative Commons licence, and indicate if changes were made. The images or other third party material in this article are included in the article's Creative Commons licence, unless indicated otherwise in a credit line to the material. If material is not included in the article's Creative Commons licence and your intended use is not permitted by statutory regulation or exceeds the permitted use, you will need to obtain permission directly from the copyright holder. To view a copy of this licence, visit http://creativecommons.org/licenses/by/4.0/.

\section{References}

Angarita-Osorio, N., Pérez-Aranda, A., Feliu-Soler, A., AndrésRodríguez, L., Borràs, X., Suso-Ribera, C., Slim, M., HerreraMercadal, P., Fernández-Vergel, R., Blanco, M. E., \& Luciano, J. V. (2019). Patients with fibromyalgia reporting severe pain but low impact of the syndrome: Clinical and pain-related cognitive features. Pain Practice, 20(3), 255-261. https://doi.org/10.1111/papr.12847

Aparicio, V. A., Ortega, F. B., Carbonell-Baeza, A., Cuevas, A. M., Delgado-Fernández, M., \& Ruiz, J. R. (2013). Anxiety, depression and fibromyalgia pain and severity. Behavioral Psychology, 21(2), 381-392.

Arnold, L. M., Gebke, K. B., \& Choy, E. H. S. (2016). Fibromyalgia: Management strategies for primary care providers. International Journal of Clinical Practice, 70(2), 99-112. https://doi.org/10. 1111/ijcp. 12757

Bolderston, H., Gillanders, D. T., Turner, G., Taylor, H. C., Ní Mhaoileoin, D., \& Coleman, A. (2019). The initial validation of a state version of the Cognitive Fusion Questionnaire. Journal of Contextual Behavioral Science, 12, 207-215. https://doi.org/10. 1016/j.jcbs.2018.04.002

Carvalho, S. A., Pinto-Gouveia, J., Gillanders, D., \& Castilho, P. (2018). Pain and depressive symptoms: Exploring cognitive fusion and selfcompassion in a moderated mediation model. The Journal of
Psychology: Interdisciplinary and Applied, 153(2), 173-186. https://doi.org/10.1080/00223980.2018.1507990

Carvalho, S. A., Trindade, I. A., Gillanders, D., Pinto-Gouveia, J., \& Castilho, P. (2019). Cognitive fusion and depressive symptoms in women with chronic pain: A longitudinal growth curve modelling study over 12-months. Clinical Psychology \& Psychotherapy, 26, 616-625. https://doi.org/10.1002/cpp.2386

Cicchetti, D. V. (1994). Guidelines, criteria, and rules of thumb for evaluating normed and standardized assessment instruments in psychology. Psychological Assessment, 6(4), 284-290. https://doi.org/10. 1037/1040-3590.6.4.284

Cincidda, C., Donati, M. A., Primi, C., Bernini, O., \& Berrocal, C. (2019). The Cognitive Fusion Questionnaire-7: Measurement invariance of the Italian version across general and clinical samples. Mediterranean Journal of Clinical Psychology, 7(2), 45-46. https:// doi.org/10.6092/2282-1619/2019.7.2268

Clauw, D. J. (2014). Fibromyalgia. JAMA, 311(15), 1547. https://doi.org/ 10.1001/jama.2014.3266.

Cohen, J. (1988). Statistical power analysis for the behavioral sciences (2nd ed.). Lawrence Erlbaum Associates.

De Ridder, D., Geenen, R., Kuijer, R., \& van Middendorp, H. (2008). Psychological adjustment to chronic disease. The Lancet, 372(9634), 246-255. https://doi.org/10.1016/s0140-6736(08) 61078-8

Écija, C., Luque-Reca, O., Suso-Ribera, C., Catala, P., \& Peñacoba, C. (2020). Associations of cognitive fusion and pain catastrophizing with fibromyalgia impact through fatigue, pain severity, and depression: An exploratory study using structural equation modeling. Journal of Clinical Medicine, 9(6), 1763. https://doi.org/10.3390/ jem9061763

Estévez-López, F., Álvarez-Gallardo, I. C., Segura-Jiménez, V., SorianoMaldonado, A., Borges-Cosic, M., Pulido-Martos, M., Aparicio, V. A., Carbonell-Baeza, A., Delgado-Fernández, M., \& Geenen, R. (2018). The discordance between subjectively and objectively measured physical function in women with fibromyalgia: Association with catastrophizing and self-efficacy cognitions. The al-Ándalus project. Disability and Rehabilitation, 40(3), 329-337. https://doi. org/10.1080/09638288.2016.1258737

Estévez-López, F., Pulido-Martos, M., Armitage, C. J., Wearden, A., Álvarez-Gallardo, I. C., Arrayás-Grajera, M. J., Girela-Rejón, M. J., Carbonell-Baeza, A., Aparicio, V. A., Geenen, R., DelgadoFernández, M., \& Segura-Jiménez, V. (2016). Factor structure of the positive and negative affect schedule (PANAS) in adult women with fibromyalgia from southern Spain: The al-Ándalus project. PeerJ, 4, e1822. https://doi.org/10.7717/peerj.1822

Garcia-Campayo, J., Rodero, B., Alda, M., Sobradiel, N., Montero, J., \& Moreno, S. (2008). Validación de la versión española de la escala de la catastrofización ante el dolor (Pain Catastrophizing Scale) en la fibromialgia. Medicina Clínica, 131(13), 487-492. https://doi.org/ $10.1157 / 13127277$

Garson, G. D. (2012). Structural equation modeling. Statistical Associates Publishers.

Gillanders, D. T., Bolderston, H., Bond, F. W., Dempster, M., Flaxman, P. E., Campbell, L., Kerr, S., Tansey, L., Noel, P., Ferenbach, P., Masley, S., Roach, L., Lloyd, J., May, L., Clarke, S., \& Remington, B. (2014). The development and initial validation of the Cognitive Fusion Questionnaire. Behavior Therapy, 45(1), 83-101. https://doi. org/10.1016/j.beth.2013.09.001

Graham, J. W. (2009). Missing data analysis: Making it work in the real world. Annual Review of Psychology, 60(1), 549-576. https://doi. org/10.1146/annurev.psych.58.110405.085530

Hair Jr., J. F., Black, W. C., Babin, B. J., \& Anderson, R. E. (2014). Multivariate data analysis (7th ed.). Pearson Education Limited.

Hankins, M. (2008). The reliability of the twelve-item general health questionnaire (GHQ-12) under realistic assumptions. BMC Public Health, 8(1). https://doi.org/10.1186/1471-2458-8-355 
Hassett, A. L., Simonelli, L. E., Radvanski, D. C., Buyske, S., Savage, S. V., \& Sigal, L. H. (2008). The relationship between affect balance style and clinical outcomes in fibromyalgia. Arthritis and Rheumatism, 59(6), 833-840. https://doi.org/10.1002/art.23708

Häuser, W., Ablin, J., Fitzcharles, M.-A., Littlejohn, G., Luciano, J. V., Usui, C., \& Walitt, B. (2015). Fibromyalgia. Nature Reviews Disease Primers, 15022. https://doi.org/10.1038/nrdp.2015.22

Hayes, S. C., Strosahl, K., \& D., \& Wilson, K. G. (2011). Acceptance and commitment therapy: The process and practice of mindful change (2nd ed.). Guilford.

Haynes, S. N., \& Lench, H. C. (2003). Incremental validity of new clinical assessment measures. Psychological Assessment, 15(4), 456466. https://doi.org/10.1037/1040-3590.15.4.456

Herrero, M. J., Blanch, J., Peri, J. M., De Pablo, J., Pintor, L., \& Bulbena, A. (2003). A validation study of the hospital anxiety and depression scale (HADS) in a Spanish population. General Hospital Psychiatry, 25(4), 277-283. https://doi.org/10.1016/s0163-8343 (03)00043-4

Hughes, L. S., Clark, J., Colclough, J. A., Dale, E., \& McMillan, D. (2017). Acceptance and commitment therapy (ACT) for chronic pain. The Clinical Journal of Pain, 33(6), 552-568. https://doi.org/ 10.1097/ajp.0000000000000425

Li, C.-H. (2016). Confirmatory factor analysis with ordinal data: Comparing robust maximum likelihood and diagonally weighted least squares. Behavior Research Methods, 48(3), 936-949. https:// doi.org/10.3758/s13428-015-0619-7

Lucena-Santos, P., Carvalho, S., Pinto-Gouveia, J., Gillanders, D., \& Silva Oliveira, M. (2017). Cognitive Fusion Questionnaire: Exploring measurement invariance across three groups of Brazilian women and the role of cognitive fusion as a mediator in the relationship between rumination and depression. Journal of Contextual Behavioral Science, 6(1), 53-62. https://doi.org/10. 1016/j.jcbs.2017.02.004

Luciano, J. V., Aguado, J., Serrano-Blanco, A., Calandre, E. P., \& Rodriguez-Lopez, C. M. (2013). Dimensionality, reliability and validity of the Revised Fibromyalgia Impact Questionnaire (FIQR) in two Spanish samples. Arthritis Care \& Research, 65(10), 16821689. https://doi.org/10.1002/acr.22034

Luciano, J. V., Barrada, J. R., Aguado, J., Osma, J., \& García-Campayo, J. (2014a). Bifactor analysis and construct validity of the HADS: A cross-sectional and longitudinal study in fibromyalgia patients. Psychological Assessment, 26(2), 395-406. https://doi.org/10. 1037/a0035284

Luciano, J. V., Guallar, J. A., Aguado, J., López-del-Hoyo, Y., Olivan, B., Magallón, R., Alda, M., Serrano-Blanco, A., Gili, M., \& GarciaCampayo, J. (2014b). Effectiveness of group acceptance and commitment therapy for fibromyalgia: A 6-month randomized controlled trial (EFFIGACT study). Pain, 155(4), 693-702. https:// doi.org/10.1016/j.pain.2013.12.029

Luoma, J. B., Hayes, S. C., \& Walser, R. D. (2007). Learning ACT: An acceptance \& commitment therapy skills-training manual for therapists. New Harbinger Publications.

Malin, K., \& Littlejohn, G. O. (2012). Neuroticism in young women with fibromyalgia links to key clinical features. Pain Research and Treatment, 2012, 1-7. https://doi.org/10.1155/2012/730741

Malin, K., \& Littlejohn, G. O. (2015). Rumination modulates stress and other psychological processes in fibromyalgia. European Journal of Rheumatology, 2(4), 143-148. https://doi.org/10.5152/eurjrheum. 2015.0005

Marôco, J. (2010). Analysis of structural equations: Theoretical foundations, software and applications. Rolo y Filhos II SA.

Masuda, A., Twohig, M. P., Stormo, A. R., Feinstein, A. B., Chou, Y.-Y., \& Wendell, J. W. (2010). The effects of cognitive defusion and thought distraction on emotional discomfort and believability of negative self-referential thoughts. Journal of Behavior Therapy and Experimental Psychiatry, 41(1), 11-17. https://doi.org/10. 1016/j.jbtep.2009.08.006

McCracken, L. M., DaSilva, P., Skillicorn, B., \& Doherty, R. (2014). The Cognitive Fusion Questionnaire: A preliminary study of psychometric properties and prediction of functioning in chronic pain. The Clinical Journal of Pain, 30(10), 894-901. https://doi.org/10.1097/ ajp.0000000000000047

Momeniarbat, F., Karimi, J., Erfani, N., \& Kiani, J. (2017). The role of neuroticism and psychological flexibility in chronic fatigue and quality of life in patients with type 2 diabetes. Romanian Journal of Diabetes Nutrition and Metabolic Diseases, 24(2), 137-148. https://doi.org/10.1515/rjdnmd-2017-0018

Munguía-Izquierdo, D., Pulido-Martos, M., Acosta, F. M., AcostaManzano, P., Gavilán-Carrera, B., Rodriguez-Ayllon, M., Geenen, R., Delgado-Fernández, M., Álvarez-Gallardo, I. C., SeguraJiménez, V., Walitt, B., \& Estévez-López, F. (2019). Objective and subjective measures of physical functioning in women with fibromyalgia: What type of measure is associated most clearly with subjective well-being? Disability and Rehabilitation, 1-8. https:// doi.org/10.1080/09638288.2019.1671503.

Özkan, S., Zale, E. L., Ring, D., \& Vranceanu, A.-M. (2017). Associations between pain catastrophizing and cognitive fusion in relation to pain and upper extremity function among hand and upper extremity surgery patients. Annals of Behavioral Medicine, 51(4), 547-554. https://doi.org/10.1007/s12160-017-9877-1

Pulido-Martos, M., Luque-Reca, O., Segura-Jiménez, V., ÁlvarezGallardo, I. C., Soriano-Maldonado, A., Acosta-Manzano, P., Gavilán-Carrera, B., McVeigh, J. G., Geenen, R., DelgadoFernández, M., \& Estévez-López, F. (2020). Physical and psychological paths toward less severe fibromyalgia: A structural equation model. Annals of Physical and Rehabilitation Medicine, 63(1), 4652. https://doi.org/10.1016/j.rehab.2019.06.017

Raykov, T. (2012). Scale construction and development using structural equation modeling. In R. H. Hoyle (Ed.), Handbook of structural equation modeling (pp. 472-492). Guildford Press.

Robinson, M. E., Staud, R., \& Price, D. D. (2013). Pain measurement and brain activity: Will neuroimages replace pain ratings? The Journal of Pain, 14(4), 323-327. https://doi.org/10.1016/j.jpain.2012.05. 007

Rodero, B., Pereira, J. P., Pérez-Yus, M. C., Casanueva, B., SerranoBlanco, A., Rodrigues da Cunha Ribeiro, M. J., Luciano, J. V., \& Garcia-Campayo, J. (2013). Validation of a Spanish version of the psychological inflexibility in pain scale (PIPS) and an evaluation of its relation with acceptance of pain and mindfulness in sample of persons with fibromyalgia. Health and Quality of Life Outcomes, 11(1), 62. https://doi.org/10.1186/1477-7525-11-62

Romero-Moreno, R., Márquez-González, M., Losada, A., Gillanders, D., \& Fernández-Fernández, V. (2014). Cognitive fusion in dementia caregiving: Psychometric properties of the Spanish version of the "Cognitive Fusion Questionnaire". Behavioral Psychology, 22(1), $117-132$

Ruiz, F. J., Odriozola-González, P., \& Suárez-Falcón, J. C. (2014). The Spanish version of the believability of anxious feelings and thoughts questionnaire. Psicothema, 26(3), 308-313. https://doi.org/10.7334/ psicothema2013.221

Salaffi, F., Di Carlo, M., Arcà, S., \& Galeazzi, M. (2018). Categorisation of disease severity states in fibromyalgia: A first step to support decision-making in health care policy. Clinical and Experimental Rheumatology, 36(6), 1074-1081.

Salgueiro, M., García-Leiva, J. M., Ballesteros, J., Hidalgo, J., Molina, R., \& Calandre, E. P. (2013). Validation of a Spanish version of the Revised Fibromyalgia Impact Questionnaire (FIQR). Health and Quality of Life Outcomes, 11(1), 132. https://doi.org/10.1186/ 1477-7525-11-132

Sandin, B., Chorot, P., Lostao, L., Joiner, T. E., Santed, M. A., \& Valiente, R. M. (1999). The PANAS scales of positive and negative 
affect: Factor analytic validation and cross-cultural convergence. Psicothema, 11(1), 37-51.

Satorra, A., \& Bentler, P. M. (1994). Corrections to test statistics and standard errors in covariance structure analysis. In A. von Eye, \& C. C. Clogg (Eds.), Latent variable analysis: Applications to developmental research (pp. 399-419). Sage.

Satorra, A., \& Bentler, P. M. (2001). A scaled difference chi-square test statistic for moment structure analysis. Psychometrika, 66(4), 507514. https://doi.org/10.1007/BF02296192

Seisdedos, N. (1999). Inventario NEO reducido de cinco factores (NEOFFI). Manual profesional [NEO-FFI Inventory. Professional manual]. TEA Ediciones.

Sicras-Mainar, A., Rejas, J., Navarro, R., Blanca, M., Morcillo, A., Larios, R., Velasco, S., \& Villarroya, C. (2009). Treating patients with fibromyalgia in primary care settings under routine medical practice: A claim database cost and burden of illness study. Arthritis Research \& Therapy, 11(2), R54. https://doi.org/10.1186/ ar2673

Sullivan, M. J. L., Bishop, S. R., \& Pivik, J. (1995). The pain catastrophizing scale: Development and validation. Psychological Assessment, 7(4), 524-532. https://doi.org/10.1037/1040-3590.7.4. 524

Suso-Ribera, C., Jornet-Gibert, M., Ribera Canudas, M. V., McCracken, L. M., Maydeu-Olivares, A., \& Gallardo-Pujol, D. (2016). There's more than catastrophizing in chronic pain: Low frustration tolerance and self-downing also predict mental health in chronic pain patients. Journal of Clinical Psychology in Medical Settings, 23(2), 192-206. https://doi.org/10.1007/s10880-016-9454-y

Ullman, J.B. (2006). Structural equation modeling. In: B.G. Tabachnick and L.S. Fidell (Eds.), Using multivariate statistics (5th ed., pp. 653-771). Allyn \& Bacon.

Trompetter, H. R., Bohlmeijer, E. T., Fox, J. P., \& Schreurs, K. M. G. (2015). Psychological flexibility and catastrophizing as associated change mechanisms during online acceptance \& commitment therapy for chronic pain. Behaviour Research and Therapy, 74, 50-59. https://doi.org/10.1016/j.brat.2015.09.001

Valdivia-Salas, S., Martín-Albo, J., Zaldivar, P., Lombas, A. S., \& Jiménez, T. I. (2016). Spanish validation of the Avoidance and Fusion Questionnaire for Youth (AFQ-Y). Assessment, 24(7), 919-931. https://doi.org/10.1177/1073191116632338

Wolfe, F., Clauw, D. J., Fitzcharles, M.-A., Goldenberg, D. L., Katz, R. S., Mease, P., Russell, A. S., Russell, I. J., Winfield, J. B., \& Yunus, M. B. (2010). The American College of Rheumatology preliminary diagnostic criteria for fibromyalgia and measurement of symptom severity. Arthritis Care \& Research, 62(5), 600-610. https://doi.org/ 10.1002/acr.20140

Wolfe, F., Smythe, H. A., Yunus, M. B., Bennett, R. M., Bombardier, C., Goldenberg, D. L., Tugwell, P., Campbell, S. M., Abeles, M., Clark, P., Fam, A. G., Farber, S. J., Fiechtner, J. J., Michael Franklin, C., Gatter, R. A., Hamaty, D., Lessard, J., Lichtbroun, A. S., Masi, A. T., et al. (1990). The American College of Rheumatology 1990 criteria for the classification of fibromyalgia: Report of the Multicenter Criteria Committee. Arthritis and Rheumatism, 33(2), 160-172. https://doi.org/10.1002/art.1780330203

Wolfe, F., Walitt, B., Perrot, S., Rasker, J. J., \& Häuser, W. (2018). Fibromyalgia diagnosis and biased assessment: Sex, prevalence and bias. PLoS One, 13(9), e0203755. https://doi.org/10.1371/ journal.pone. 0203755

Zigmond, A. S., \& Snaith, R. P. (1983). The hospital anxiety and depression scale. Acta Psychiatrica Scandinavica, 67(6), 361-370. https:// doi.org/10.1111/j.1600-0447.1983.tb09716.x

Publisher's Note Springer Nature remains neutral with regard to jurisdictional claims in published maps and institutional affiliations. 